\title{
Evaluation of subunit vaccines against feline immunodeficiency virus infection
}

\author{
Ernst J. Verschoor*, Marja J. Willemse†, Jeanette G. Stam, \\ Arno L.W. van Vliet*, Henk Pouwels $\dagger$, Stuart K. Chalmerst, \\ Marian C. Horzinek*, Paul J.A. Sondermeijer $\dagger$, Wim Hesselink $\dagger$ and \\ Anthony de Ronde* $\neq \S$
}

\begin{abstract}
Subunit vaccines prepared against feline immunodeficiency virus (FIV) infection were evaluated in two trials. First. cats were immunized with bacterial expression products of an envelope fragment that contained the V3 neutralization domain of the FIV surface protein fused to either galactokinase (K-SU3) or glutathione-S-transferase (G-SU3). Quantitative and qualitative differences in the humoral immune response were observed with three adjuvants of which Quil $A$ was the best in terms of total and virus neutralizing antibody. Notwithstanding the responses induced, 19 of 20 immunized cats did not resist challenge and became infected. To determine whether priming with a live viral vector would confer protection, cats were inoculated oronasally and subcutaneously with a feline herpesvirus (FHV) mutant expressing the FIV env gene; two booster immunizations followed using the $K$-SU3 product in either Quil $A$ or a mineral oill Al $(\mathrm{OH})_{3}$ adjuvant. FIV-specific antibody responses were only weak, and the vaccinates did not withstand challenge with a low' dose of homologous virus. Copyright (C) 1996 Elsevier Science Ltd.
\end{abstract}

Keywords: Feline immunodeficiency virus: FIV; vaccination: subunit vaccine; feline herpesvirus vector

Since the onset of the AIDS epidemic and the following identification of a lentivirus, the human immunodeficiency virus type 1 (HIV-1) as its cause ${ }^{1,2}$, development of an HIV vaccine has become an important objective. A convenient small animal model has been found in feline immunodeficiency virus (FIV) infection of cats that can be exploited for the study of lentivirus pathogenesis and vaccine development ${ }^{3-5}$. Like HIV-1, FIV causes an immunodeficiency syndrome in its host. The virus is more prevalent in the cat population than HIV is in man, and development of a vaccine is therefore of obvious veterinary importance.

Lentiviral vaccine studies have met with varying degrees of success ${ }^{6-13}$. Cats have been protected against homologous and heterologous FIV challenge using whole-virus and fixed-infected cell vaccines ${ }^{14.15}$. Passive immunization has demonstrated the protective potential of antibodies against FIV infection ${ }^{16}$. Their nature and the epitopes to which they are directed are as yet unknown. High-titered virus neutralizing antibody (VNA) responses can be elicited in cats by immunization

\footnotetext{
*Virology Unit, Institute of Infectious Diseases and Immunology, Veterinary Faculty, University Utrecht, Yalelaan 1, 3584 $\mathrm{CL}$, Utrecht, The Netherlands. IIntervet International BV, PO Box 31, 5830 AA, Boxmeer, The Netherlands. \$Present address: Human Retrovirus Laboratory, Academic Medical Center, Meibergdreef 15, 1105 AZ, Amsterdam, The Netherlands. §To whom correspondence should be addressed. (Received 16 May 1995; revised 7 September 1995; accepted 12 September 1995)
}

with the V3 region of the FIV envelope surface (SU) protein $^{17,18}$. Moreover, the V3 region acts as an immunodominant neutralization domain in FIV-infected cats $^{18}$ and determines cell tropism in vitro ${ }^{19}$; it has these properties in common with its HIV-1 counterpart ${ }^{20}$.

We have used bacterial expression products containing the FIV V3 region in the vaccination experiments. The polypeptides proteins were presented in combination with three different adjuvants: a mineral oil/ $\mathrm{Al}(\mathrm{OH})_{3}$-based adjuvant, Quil A, and a combination of Quil $\mathrm{A}$ and $\mathrm{Al}(\mathrm{OII})_{3}$ were used.

In the second part of this study we primed the immune system with a live-attenuated feline herpesvirus-1 (FHV-1) vector expressing the FIV env gene, combined with booster immunizations with the V3-containing protein. All vaccination protocols were tested for their ability to protect against FIV by challenging the cats with a low dose of the homologous strain FIV-UT113.

\section{MATERIALS AND METHODS}

\section{Bacterial fusion proteins}

Two Escherichia coli expression products were used which consisted of the amino acid residues 361-445 of the FIV SU protein fused to galactokinase (K-SU3) or glutathione-S-transferase (G-SU3). The SU moiety encodes an immunodominant epitope that was shown to induce VNA in cats ${ }^{18}$. Expression and purification of the fusion proteins has been described previously ${ }^{18}$. 
Table 1 Vaccine formulations and vaccination schedules

\begin{tabular}{|c|c|c|c|c|c|c|c|}
\hline \multirow{3}{*}{$\begin{array}{l}\text { Trial } \\
\text { Group }\end{array}$} & \multirow[b]{3}{*}{ Animal } & \multicolumn{6}{|l|}{ Vaccination } \\
\hline & & \multirow[b]{2}{*}{ Adjuvant } & \multicolumn{5}{|l|}{ Antigen } \\
\hline & & & Week 0 & Week 4 & Week 6 & Week 8 & Week 10 \\
\hline \multicolumn{8}{|l|}{ Trial 1} \\
\hline & $1-5$ & Mineral oil/Al $(\mathrm{OH})_{3}$ & K-SU3 & K-SU3 & K-SU3 & K-SU3 & K-SU3 \\
\hline iI & $5-10$ & Mineral oil/Al $(\mathrm{OH})_{3}$ & K-SU3 & K-SU3 & K-SU3 & K-SU3 & G-SU3 \\
\hline iil & $11-15$ & Quil A & K-SU3 & PBS & K-SU3 & PBS & K-SU3 \\
\hline IV & $16-20$ & Quil $\mathrm{A} / \mathrm{Al}(\mathrm{OH})_{3}$ & K-SU3 & & K-SU3 & & G-SU3 \\
\hline $\begin{array}{l}V \\
\text { Trial } 2\end{array}$ & $21-25$ & Controls & PBS & & PBS & & PBS \\
\hline 1 & $1-5$ & Mineral oil/Al $(\mathrm{OH})_{3}$ & FHV-FIV-env & & & & \\
\hline II & $6-10$ & Quil A & FHV-FIV-env & & & & \\
\hline III & $11-15$ & Controls & $\mathrm{FHV} / \beta$-gal & & & & \\
\hline
\end{tabular}

\section{Vaccine preparation}

Antigen was mixed with adjuvant to a concentration of $100 \mu \mathrm{g} \mathrm{ml}^{-1}$ of vaccine; the respective adjuvants are listed in Table 1. The oil/Al $(\mathrm{OH})_{3}$-based vaccines were water-in-mineral oil emulsions with the antigen absorbed to alum in the water phase. Saponin Quil A was used in two adjuvant formulations: either antigen was mixed with Quil A directly (100 $\mu \mathrm{g} \mathrm{ml}$ '; Superfos, Vedbaek, Denmark) or after pre-absorption to $0.3 \%$ (final concentration) of $\mathrm{Al}(\mathrm{OH})_{3}$ gel (Superfos, Vedbaek, Denmark). Phosphate-buffered saline (PBS) was used as placebo vaccine. Each adjuvant formulation contained $0.01 \%$ thiomersal for preservation and was stored at $4^{\circ} \mathrm{C}$ until use.

\section{Construction of recombinant FHV virus vectors}

Recombinant FHV viruses were developed that express either the $E$. coli $\beta$-galactosidase gene or the envelope gene of FIV-UT113 (EMBL accession no. $\mathrm{X} 60725)^{21}$. The development of the FHV/ $\beta$-gal vector, strain $25 \mathrm{~B} 3 \mathrm{~B} 11$, has been described before ${ }^{22}$. The construction of FHV/FIV-env vector was essentially as described for $\mathrm{FHV} / \beta$-gal, using the same insertion site in the $U_{L}$ region. However, to drive the expression of the FIV gene a strong promotor was selected that had been derived from the long terminal repeat (LTR) of Rous sarcoma virus ${ }^{23}$. The resultant transfer plasmid pFHV37 was co-transfected with FHV DNA into CRFK cells and recombinant viruses were generated by homologous recombination. Recombinant viruses were detected by immunofluorescence and stocks were prepared by plaque-purification.

\section{Design of the trials}

Trial 1. All cats were vaccinated at 0,6 , and 10 weeks with $1 \mathrm{ml}$ of vaccine; challenge was by subcutaneous (s.c.) injection of $10-2050 \%$ cat infectious doses $\left(\right.$ CID $\left._{50}\right)$ of FIV-UT113 at week 14 (Table 1). Four groups of 5 cats each were vaccinated with the fusion proteins while one group of 5 cats was immunized with the placebo vaccine. Mineral oil/Al $(\mathrm{OH})_{3}$-based vaccines were given intramuscularly (i.m.) while the other vaccines were applied subcutaneously (s.c.). Group I was vaccinated three times with $100 \mu \mathrm{g}$ of K-SU3. Groups II, III, and IV were immunized twice ( $t=0$ and 6 weeks) with $100 \mu \mathrm{g}$ of $\mathrm{K}-\mathrm{SU} 3$ and received a final booster immunization with $100 \mu \mathrm{g}$ of G-SU3 at week 10. Cats in group $V$ received three immunizations with PBS.

Trial 2. Three groups of 5 cats were used in this study. At $t=0$ weeks cats from groups I and II were inoculated oronasally and s.c. with $10^{5}$ plaque-forming units (p.f.u.) of the FHV/FIV-env recombinant while group III was inoculated via both routes with $10^{5}$ p.f.u. of the FHV $/ \beta$-gal vector. At 4 and 8 weeks after priming with the FHV recombinants all animals received booster injections. Group I was immunized i.m. with $100 \mu \mathrm{g}$ $\mathrm{K}-\mathrm{SU} 3 /$ dose in mineral oil/ $\mathrm{Al}(\mathrm{OH})_{3}$ adjuvant. Group II received the same antigen s.c., formulated in Quil A adjuvant, while group III was s.c. immunized twice with PBS (Table 1). At $t=12$ weeks the animals were challenged s.c. with $10-20 \mathrm{CID}_{50}$ of FIV-UT113.

\section{Virus isolation and serology}

Blood samples were taken for serology and virus isolation at regular intervals. Isolation of FIV from peripheral blood mononuclear cells was described earlier ${ }^{24}$. FHV was isolated from oropharyngeal swabs as described by Willemse $e t a l .^{22}$

Antibodies directed to the FIV core and envelope proteins were detected by an F.LISA based on gag and env expression products ${ }^{25}$. VNA titers were determined in CRFK cells ${ }^{18}$. VNA titers were defined as the reciprocal of the highest dilution at which the virus was completely neutralized.

\section{RESULTS}

\section{Vaccine trial 1}

Development of antibody after immunization with the fusion proteins was measured in an ELISA using baculovirus-expressed gp150 envelope protein. Differences in kinetics and strength of the anti-envelope response between the immunization groups could be distinguished (Figure $I$ ). A rapid antibody response was observed in the Quil A (group III) vaccinees; after two immunizations this group had a mean response twice as high as the others. At challenge (week 14) cats in the oil/Al(OH) (group II) and Quil A (group III) sets had generated the highest FIV-specific antibody response. All SU3-vaccinated groups had a mean anti-envelope 


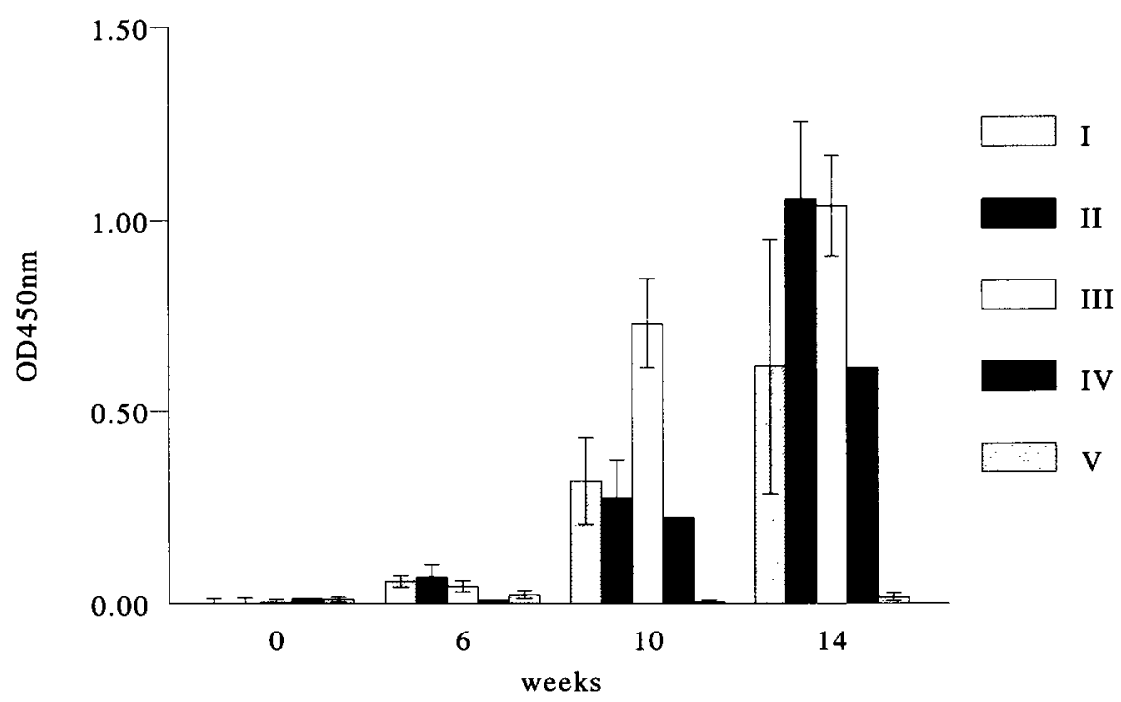

Figure 1 Envelope antibody responses of cats immunized with different adjuvant formulations. Mean responses for each vaccine group are represented by bars

Table 2 Antibody titers and virus isolation (trial 1)

\begin{tabular}{|c|c|c|c|c|c|c|}
\hline \multirow[b]{2}{*}{ Group } & \multirow[b]{2}{*}{ Cat } & \multirow[b]{2}{*}{$\mathrm{AB}^{a}$} & \multicolumn{2}{|l|}{ VNA $^{b}$} & \multirow[b]{2}{*}{$V I^{c}$} & \multirow[b]{2}{*}{ Seroresp } \\
\hline & & & Week 10 & Week 14 & & \\
\hline \multirow{6}{*}{1} & 1 & 400 & 16 & 16 & + & $+/ t$ \\
\hline & 2 & 800 & $<16$ & 256 & + & $+/+$ \\
\hline & 3 & 800 & 64 & 256 & - & $+1+$ \\
\hline & 4 & 800 & 16 & 16 & - & $+1+$ \\
\hline & 5 & 800 & 16 & 64 & + & $+1+$ \\
\hline & 6 & 1600 & 16 & 256 & + & $-/ \pm$ \\
\hline & 7 & 400 & 64 & 64 & + & $+1+$ \\
\hline \multirow[t]{2}{*}{ II } & 8 & 800 & 64 & 16 & + & $+1+$ \\
\hline & 9 & 1600 & 64 & 64 & + & $+1+$ \\
\hline \multirow{7}{*}{ III } & 10 & 1600 & 256 & 256 & + & $+1+$ \\
\hline & 11 & 1600 & 64 & 256 & - & $\pm /-$ \\
\hline & 12 & 3200 & 256 & 256 & + & $+1+$ \\
\hline & 13 & 3200 & 256 & 256 & + & $+1+$ \\
\hline & 14 & $1600-3200$ & 64 & 16 & + & $+1-$ \\
\hline & 15 & 3200 & 1024 & 256 & - & $-1 \pm$ \\
\hline & 16 & 200 & 64 & 16 & + & $+1+$ \\
\hline \multirow{4}{*}{ IV } & 17 & $200-400$ & 64 & 64 & - & $-/+$ \\
\hline & 18 & 800 & 64 & 256 & + & $+1+$ \\
\hline & 19 & 400 & $<16$ & 64 & + & $+1+$ \\
\hline & 20 & 800 & 64 & 256 & + & $+1+$ \\
\hline \multirow{5}{*}{ V } & 21 & $<100$ & $<16$ & $<16$ & + & $+1+$ \\
\hline & 22 & $<100$ & $<16$ & $<16$ & - & $-/-$ \\
\hline & 23 & $<100$ & $<16$ & $<16$ & + & $+1+$ \\
\hline & 24 & $<100$ & $<16$ & $<16$ & + & $+1+$ \\
\hline & 25 & $<100$ & $<16$ & $<16$ & + & $\pm /-$ \\
\hline
\end{tabular}

${ }^{2}$ Antibody titer to the FIV envelope protein at moment of challenge ( $t=14$ weeks). Virus neutralizing antibody titer at $t=10$ and 14 weeks after first immunization. Virus isolation from PBMC cultures; $(-)$ negative at each time point; $(+)$, positive at one or more time points. ${ }^{\circ}$ Seroresponse after challenge (VNA/ELISA); $(-)$ no increase in antibody response; $(+)$ increase in antibody titer; $( \pm)$ indefinite

response exceeding that of our control serum taken from a FIV-infected cat $(0.583 \pm 0.033)$. VNA titers were tested before challenge at week 10 and 14 (Table 2). A correlation was discernible between the total anti-FIV response and the VNA titer though an exception could be found (cat no. 14).

Fourteen weeks after the first immunization all cats were challenged with $10-20 \mathrm{CID}_{50}$ of homologous FIVUT113. Virus isolation from PBMC and antibody titers were used to assess vaccine efficacy. The post-challenge data are listed in Table 2. Virus isolation was possible from PBMC cultures of 19 cats. However, 22 of 25 cats
Table 3 Antibody response and virus isolation (trial 2)

\begin{tabular}{|c|c|c|c|c|c|}
\hline \multirow[b]{2}{*}{ Group } & \multirow[b]{2}{*}{ Cat } & \multicolumn{2}{|l|}{ VNA titer } & \multirow[b]{2}{*}{$\mathrm{VR}^{a}$} & \multirow[b]{2}{*}{ Seroresp $p^{b}$} \\
\hline & & Week 8 & Week 12 & & \\
\hline \multirow{6}{*}{1} & $\mid-31$ & $<16$ & 16 & + & + \\
\hline & $1-39$ & $<16$ & 16 & + & + \\
\hline & $\mid-43$ & 16 & 16 & + & + \\
\hline & $1-46$ & $<16$ & 16 & + & + \\
\hline & $1-65$ & $<16$ & 16 & + & + \\
\hline & $\mid-42$ & $<16$ & 16 & + & + \\
\hline \multirow{3}{*}{ II } & $\mid-50$ & $<16$ & 16 & + & + \\
\hline & $\mid-51$ & $<16$ & 256 & + & + \\
\hline & $1-57$ & 16 & ND & + & + \\
\hline \multirow{6}{*}{ III } & $1-63$ & 16 & 64 & + & + \\
\hline & $\mid-27$ & $<16$ & 16 & + & + \\
\hline & $1-37$ & $<16$ & $<16$ & + & + \\
\hline & $\mid-44$ & $<16$ & $<16$ & + & + \\
\hline & $\mid-52$ & $<16$ & $<16$ & + & + \\
\hline & $1-62$ & $<16$ & $<16$ & + & + \\
\hline
\end{tabular}

Pre-challenge VNA titers were determined 8 and 12 weeks after the start of the trial. ${ }^{2}$ Virus isolation after challenge. ${ }^{b}$ Seroresponse after challenge (VNA); $(+)$, positive in virus isolation from PBMC cultures at one or more time points or increase in VNA titer after challenge; $(-)$ negative in virus isolation from PBMC cultures at all time points or lack of increase VNA titer after challenge

were considered as virus-infected when these data were analyzed in combination with the seroresponses after challenge. One PBS control cat (cat no. 22) remained protected against FIV challenge. Interestingly, this animal withstood a second challenge with $10-20 \mathrm{CID}_{50}$ of FIV-UT113 at $t=22$ weeks, a phenomenon we also have encountered in other vaccine trials ${ }^{24}$.

\section{Vaccine trial 2}

Four weeks after oronasal inoculation with the FHV recombinant sera were screened for FIV-specific antibodies. No humoral response was detectable in an immunoprecipitation assay using radiolabelled FIV ${ }^{21}$ (data not shown). Subsequent booster immunizations with the bacterial fusion protein K-SU3 induced low levcls of FIV-specific antibodies (Figure 2), as well as low VNA titers (Table 3). Quantitative differences in total anti-envelope antibodies and VNA responses between groups I and II were noticeable, similar to those 


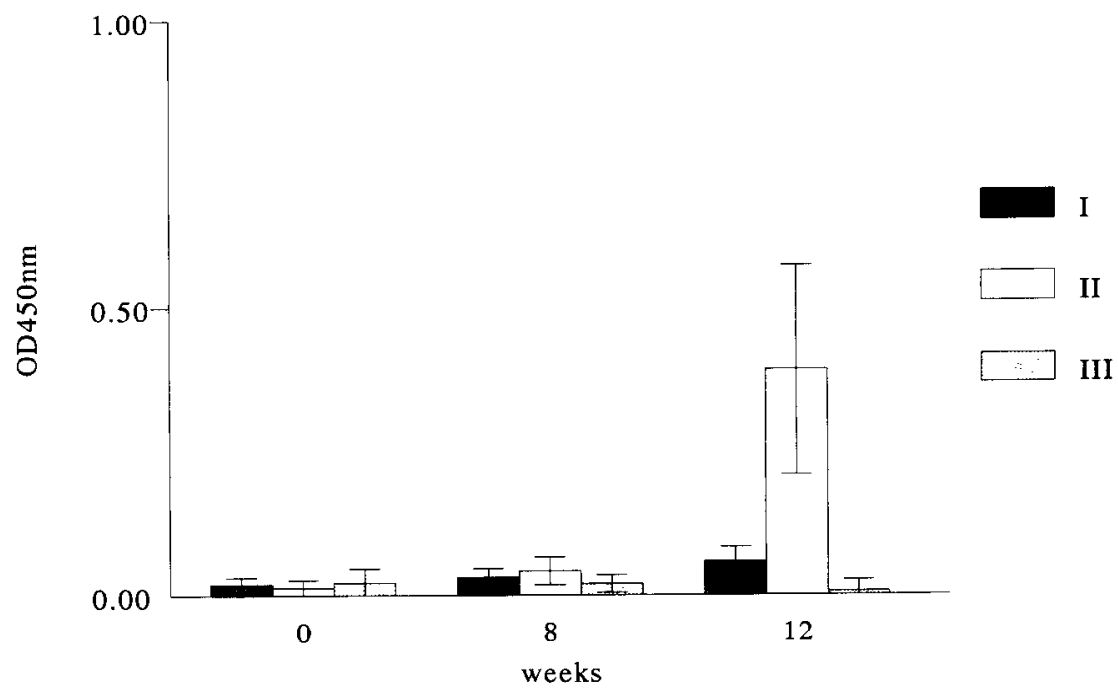

Figure 2 Development of FIV-specific antibody response after immunization of cats with a live virus vector (FHV/FIV-env or FHV/ $\beta$-gal) in combination with subunit booster immunizations at $t=4$ and 8 weeks. Mean responses for each vaccine group are represented by bars

in trial 1. Upon challenge all cats became infected as evidenced by virus isolation from PBMC cultures and by a further rise in antibody titers (Table 3).

\section{DISCUSSION}

In this study we examined whether V3-fusion proteins could protect cats against an FIV challenge. Both peptides were previously shown to be immunogenic in cats and able to induce VNA ${ }^{18}$. Our protocol consisted of three immunizations within a 3-month period; variations were made in the antigen used for final booster immunization and in the adjuvant formulation. G-SU3 was incorporated in final immunization to specifically boost the SU3-directed immune response and not that to the galactokinase (K-) part of the immunogen. Use of G-SU3 in the final immunization considerably increased the FIV-specific antibody levels. The adjuvants used are all applied in veterinary practice and were selected on the basis of their potential to induce divergent immune responses. Quil A stimulates both humoral and cellmediated immunity ${ }^{26.27}$. $\mathrm{Oil} / \mathrm{Al}(\mathrm{OH})_{3}$ induces mainly the humoral immunity ${ }^{28}$ while $\mathrm{Al}(\mathrm{OH})_{3}$ can strongly potentiate the adjuvanticity of Quil $\mathrm{A}^{29.30}$

The Quil A vaccine had induced the strongest humoral response after two immunizations. Strong and rapid immunoresponses after use of Quil A-containing vaccines are also reported by others ${ }^{31-33}$. At challenge the mineral oil/ $\mathrm{Al}(\mathrm{OH})_{3}$ vaccination group had a mean antibody titer comparable to that of the Quil A group. $\mathrm{Al}(\mathrm{OH})_{3}$ in combination with Quil A (group IV) was successfully employed in a feline leukaemia virus subunit vaccine with $E$. coli-expressed gp 70 as antigen ${ }^{34}$, but in our experiments the combination negatively influenced the level and quality (VNA) of the response. Such a phenomenon has been described by Bomford et al. ${ }^{30}$ who reported a relation between efficacy of the combination-adjuvant and the immunogenicity of the antigen.

Priming with a FHV/FIV-env recombinant in combination with two booster immunizations was also examined for its protective capacity. The rationale for such a protocol was that both cell-mediated and humoral immunity would be induced. Similar protocols have been successful in protecting macaques and chimpanzees against SIV and HIV-1 infection, respectively ${ }^{1,8}$. The reason for the failure to induce protection in our experiments remains as yet to be elucidated. The FHV/FIVenv recombinant replicated well as it could be routinely reisolated until 3 weeks after inoculation (data not shown). In addition, it was capable of eliciting protection to a virulent FHV strain in an earlier study (M.W., unpublished observations). Local nature of the immune responses induced by FHV, which primarily replicates in the oronasal tract, may have contributed to the lack of protection against subcutaneous FIV challenge whereas systemic immunity is preferred. We attempted to overcome this limitation by s.c. inoculation of the FHV recombinants in combination with intramuscular boostering of the animals with the V3-containing protein. A similar protocol successfully protected cats against i.m. inoculation with the feline retrovirus FeLV ${ }^{35}$. The antibody response elicited after the two booster immunizations with the SU3 protein was weaker than after immunization with only the protein and may suggest interference by the priming with the FHV/FIV-env vector.

Our efforts to induce immunity to FIV infection have failed. Successful protection against FIV has been obtained by a vaccine consisting of fixed-FIV-infected T-cells (FL-4 cells) ${ }^{14.15}$. Passive transfer of serum from immunized animals can prevent cats from FIV infection, indicating that antibodies can protect ${ }^{16}$. The nature of these protective antibodies and the epitopes to which they are directed are unknown. Failure to elicit protective antibodies in our study, despite induction of high anti-envelope antibody responses, may indicate that epitopes other than within the V3 region may be involved or that in vitro (VNA) titers cannot be directly translated to the in vivo situation. Fnhancement of infection after the immunization with FIV subunit vaccines has been observed too ${ }^{36-38}$. We have not encountered the latter event as post-challenge titers and virus isolations from vaccinated animals were comparable to those of the controls. However, the design of our study, particularly the infrequent sampling immediately following challenge, may have prevented detection of enhancement. The observation of enhancement illustrates that 
FIV vaccination may not always be beneficial and once again emphasizes the many obstacles which may be encountered during the development of an efficacious lentivirus vaccine.

\section{REFERENCES}

1 Gallo, R.C., Salahuddin, S.Z., Popovic, M. et al. Frequent detection and isolation of cytopathic retroviruses (HTLV-III) from patients with AIDS and at risk for AIDS. Science 1984, 224, 500-503

2 Barré-Sinoussi, F., Chermann, J.C., Rey, F. et al. Isolation of a T-lymphotropic retrovirus from a patient at risk for acquired immune deficiency syndrome (AIDS). Science 1983, 220, 868871

3 Jarrett, O., Yamamoto, J.K. and Neil, J.C. Feline immunodeficiency virus as a model for AIDS vaccination. AIDS 1990, 4 Suppl. 1, S163-S165

4 Egberink, H. and Horzinek, M.C. Animal immunodeficiency viruses. Vet. Microbiol. 1992, 33, 311-331

5 Bendinelli, M., Pistello, M., Matteucci, D. et al. Small animal model of AIDS and the feline immunodeficiency virus. Adv. Exp. Med. Biol. 1993, 335, 189-202

6 Berman, P.W., Gregory, T.J., Riddle, L. et al. Protection of chimpanzees from infection by HIV-1 after vaccination with recombinant glycoprotein gp120 but not gp160. Nature 1990, 345, 622-625

7 Girard, M., Kieny, M.-P., Pinter, A. et al. Immunization of chimpanzees confers protection against challenge with human immunodeficiency virus. Proc. Natl Acad. Sci. USA 1991, 88, $542-546$

8 Hu, S.-L., Abrams, K., Barber, G.N. et al. Protection of macaques against SIV infection by subunit vaccines of SIV envelope glycoprotein gp160. Science 1992, 255, 456-459

9 Issel, C.J., Horohov, D.W., Lea, D.F. et al. Efficacy of inactivated whole-virus and subunit vaccines in preventing infection and disease caused by equine infectious anemia virus. J. Virol. 1992, 66, 3398-3408

10 Fultz, P.N., Nara, P., Barré-Sinoussi, F. et al. Vaccine protection of chimpanzees against challenge with HIV- 1 infected peripheral blood mononuclear cells. Science 1992, 256, 1687-1690

11 Heeney, J.L., De Vries, P., Dubbes, R. et al. Comparison of protection from homologous cell-free vs cell-associated SIV challenge afforded by inactivated whole SIV vaccines. J. Med. Primatol. 1992, 21, 126-130

12 Daniel, M.D., Kirchhoff, F., Czajak, S.C., Sehgal, P.K and Desrosiers, R.C. Protective effects of a live attenuated SIV vaccine with a deletion in the nef gene. Science 1992, 258, 1938-1941

13 Heeney, J.L., Holterman, L., ten Haaft, P. et al. Vaccine protection and reduced virus load from heterologous macaquepropagated SIV challenge. AIDS Res. Hum. Retrovir. 1994, 10 Suppl. 2, S117-S121

14 Yamamoto, J.K., Okuda, T., Ackley, C.D. et al. Experimental vaccine protection against feline immunodeficiency virus. AIDS Res. Hum. Retrovir. 1991, 7, 911-922

15 Yamamoto, J.K., Hohdatsu, T., Olmsted, R.A. et al. Experimental vaccine protection against homologous and heterologous strains of feline immunodeficiency virus. J. Virol. 1993, 67, $601-605$

16 Hohdatsu, T., Pu, R., Torres, B.A., Trujillo, S., Gardner, M.B. and Yamamoto, J.K. Passive antibody protection of cats against feline immunodeficiency virus infection. J. Virol. 1993, 67, 2344-2348

17 Lombardi, S., Garzelli, C., La Rosa, C. ef al. Identification of a linear neutralization site within the third variable region of the feline immunodeficiency virus envelope. J. Virol. 1993, 67, 4742-4749

18 De Ronde, A., Stam, J.G., Boers, P. et al. Antibody response in cats to the envelope proteins of feline immunodeficiency virus: identification of an immunodominant neutralization domain. Virology 1994, 198, 257-264
19 Verschoor, E.J., Boven, L.A., Blaak, H., Van Vliet, A.L.W. Horzinek, M.C. and De Ronde, A. A single mutation within the V3 envelope neutralization domain of feline immunodeficiency virus determines its tropism for CRFK cells. J. Virol. 1995, $\mathbf{6 9}$, $4752-4757$

20 Levy, J.A. Pathogenesis of human immunodeficiency virus infection. Microbiol. Rev. 1993, 57, 183-289

21 Verschoor, E.J., Hulskotte, E.G.J., Ederveen, J., Koolen, M.J.M., Horzinek, M.C. and Rottier, P.J.M. Post-translationa processing of the feline immunodeficiency virus envelope precursor protein. Virology 1993, 193, 433-438

22 Willemse, M.J., Chalmers, W.S.K., Cronenberg, A.M., Pfundt R., Strijdveen, I.G.L. and Sondermeijer, P.J.A. The gene downsteam of the $\mathrm{gC}$ homologue in feline herpes virus type 1 is involved in the expression of virulence. J. Gen. Virol 1994, 75 3107-3116

23 Sondermeijer, P.J.A., Claessens, J.A.J., Jenniskens, P.E. et al Avian herpesvirus as a live viral vector for the expression of heterologous antigens. Vaccine 1993, 11, 349-358

24 Verschoor, E.J., Van Vliet, A.L.W. Egberink, H.F. et al Vaccination against feline immunodeficiency virus using fixed infected cells. Vet. Immunol. Immunopathol. 1995, 46, 139-149

25 Verschoor, E.J., Van Vliet, A.L.W., Egberink, H.F., Hesselink W., Horzinek, M.C. and De Ronde, A. Expression of feline immunodeficiency virus gag and env precursor proteins in Spodoptera frugiperda cells and their use in immunodiagnosis. J. Clin. Microbiol. 1993, 31, 2350-2355

26 Bomford, R., Stapleton, M., Winsor, S., McKnight, A. and Andronova, T. The control of the antibody isotype response to recombinant human immunodeficiency virus gp120 antigen by adjuvants. AIDS Res. Hum. Retrovir. 1992, 8, 1765-1771

27 Newman, M.J., Wu, J.-Y., Gardner, B.H. et al. Saponin adjuvant induction of ovalbumin-specific CD8+ cytotoxic T lymphocyte responses. J. Immunol. 1992, 148, 2357 2362

28 Hem, S.L. and White, J.L. Characterization of aluminium hydroxide for use as an adjuvant in parenteral vaccines. J. Parent. Sci. Technol. 1984, 38, 2-10

29 Wu, J.-Y., Gardner, B.H., Murphy, C.I. et al. Saponin adjuvant enhancement of antigen-specific immune responses to an experimental HIV-1 vaccine. J. Immunol. 1992, 148, 1519-1525

30 Bomford, R. Relative adjuvant efficacy of $\mathrm{Al}(\mathrm{OH})_{3}$ and saponin is related to the immunogenicity of the antigen. Int. Archs Allergy Appl. Immunol. 1984, 75, 280-281

31 Osterhaus, A., Weijer, K., Uytdehaag, F. et al. Serological responses in cats vaccinated with FeLV ISCOM and an inactivated FeLV vaccine. Vaccine 1989, 7, 137-141

32 Pyle, S.W., Morein, B., Bess, J.W. et al. Immune response to immunostimulatory complexes (ISCOMs) prepared from human immunodeficiency virus type 1 (HIV-1) or the HIV-1 external envelope glycoprotein (gp120). Vaccine 1989, 7, 465-473

33 Powell, M.F., Cleland, J.L., Eastman, D.J. et al. Immunogenicity and HIV-1 virus neutralization of MN recombinant glycoprotein 120/HIV-1 QS21 vaccine in baboons. AIDS Res. Hum. Retrovir. 1994, 10 Suppl. 2, S105-S108

34 Marciani, D.J., Kensil, C.R., Beltz, G.A., Hung, C., Cronier, J. and Aubert, A. Genetically-engineered subunit vaccine against feline leukaemia virus: protective immune response in cats. Vaccine 1991, 9, 89-96

35 Wardley, R.C., Berlinski, P.J., Thomsen, D.R., Meyer, A.L. and Post, L.E. The use of feline herpesvirus and baculovirus as vaccine vectors for the gag and env genes of feline leukaemia virus. J. Gen. Virol. 1992, 73, 1811-1818

36 Hosie, M.J., Osborne, R., Reid, G., Neil, J.C. and Jarrett, O Enhancement after feline immunodeficiency virus vaccination. Vet. Immunol. Immunopathol. 1992, 35, 191-197

37 Siebelink, K.H.J., Tijhaar, E., Huisman, R.C. et al. Enhancement of feline immunodeficiency virus infectivity after immunization with envelope glycoprotein subunit vaccines. J. Virol. $1995,69,3704-3711$

38 Lombardi, S., Garzelli, C., Pistello, M. et al. A neutralizing antibody-inducing peptide of the $V 3$ domain of feline immunodeficiency virus envelope glycoprotein does not induce protective immunity. J. Virol. 1994, 68, 8374-8379 